\title{
Fascinating Technology
}

\section{Dear Reader,}

Anyone who has ever been to bauma in Munich will agree: construction machines are fascinating! Even the view of the fairgrounds alone when one arrives by car is impressive. Huge cranes stretching into the sky can be seen from far away. But the vast open-air exhibition ground is not only an arena for cranes, but also for all kinds of mobile machines and off-road vehicles. And the presentations given by the vehicles not only attract specialist engineers, but also crowds of wide-eyed youngsters. This is what sets this fair apart in a positive way from so many other trade fairs.

However, most of the visitors are not only interested in the shows. Their focus is also on the detailed technical solutions that distinguish one construction machine from another. And it is not only high-tech engineering that is in demand, but also robust solutions for emerging markets. In our first cover story, we therefore present a new non-road engine family that has been specially developed for the challenges of these markets and takes into account the wide variety of possible applications. The second cover story also addresses an important topic: reducing vibration loads on wheel loader drivers. The cover stories are rounded off by an interview with Dr. Marko Dekena, Executive Vice President at AVL, on the trends and challenges in the construction machine sector. Further interesting reports on the main topics of tractors, many of which are also used in professional construction site applications, as well as powertrains and simulation round off this issue.

But it is not only the technology that we report on that is continuously further developing. Ever since ATZoffhighway was first published in 2008, we have successively increased our numbers of readers, subscribers and advertising customers as a result of our detailed technical reports. The level of familiarity of our magazine has also continuously increased. For that reason, our publisher has decided this year to publish ATZoffhighway four times a year. At the same time, we are separating the German and English sections, starting with the current issue. In order to support their international distribution, the English reports will in future be published in a digital interactive e-magazine. The German articles will continue to be published as before in a printed version, but at the same time they will also appear as a new e-magazine. And the best news: This additional service is free of charge for our subscribers.

I look forward to meeting you in Munich.

Best regards,

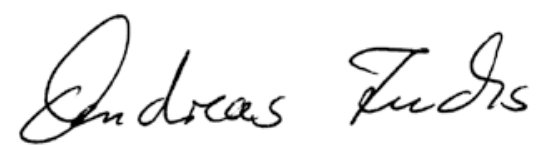

Dipl.-Ing. (FH) Andreas Fuchs

Chief Correspondent

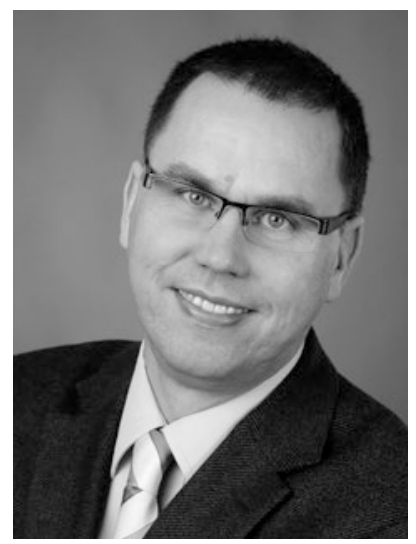

